\title{
Cleaner shrimp remove parasite eggs on fish cages
}

\author{
David B. Vaughan ${ }^{1, *}$, Alexandra S. Grutter ${ }^{2}$, Kate S. Hutson ${ }^{1}$ \\ ${ }^{1}$ Centre for Sustainable Tropical Fisheries and Aquaculture, College of Science and Engineering, James Cook University, \\ Townsville QLD 4811, Australia \\ ${ }^{2}$ School of Biological Sciences, The University of Queensland, St Lucia, QLD 4072, Australia
}

\begin{abstract}
Benthic stages of cultured fishes' ectoparasites are a major contributor to persistent reinfections in aquaculture. These stages are resistant to chemical therapies and are costly to manage in terms of time and labour. Cleaner shrimp, unlike cleaner fishes, prey on benthic stages, suggesting they have the potential to reduce parasite reinfection pressure without having to be in direct contact with the client fish. Cleaner shrimp have never been used as biocontrols in commercial aquaculture, but offer an advantage over cleaner fishes in that they are not susceptible to the ectoparasites of their clients. We present the first investigation of a cultured cleaner shrimp, Lysmata vittata, as a biocontrol agent against the eggs of the economically important cosmopolitan ectoparasite Neobenedenia girellae infecting cultured juvenile grouper, Epinephelus lanceolatus, under simulated recirculating aquaculture conditions. L. vittata removed the eggs of $N$. girellae entangled on the mesh of the culture cages and significantly reduced $N$. girellae recruitment to fish by $\sim 87 \%$. Our results demonstrate the value of cleaner shrimp in addressing ectoparasite problems and highlight the importance of investigating novel biocontrol strategies in aquaculture.
\end{abstract}

KEY WORDS: Biocontrol $\cdot$ Cleaner shrimp $\cdot$ Lysmata vittata $\cdot$ Aquaculture $\cdot$ Ectoparasites

\section{INTRODUCTION}

Biocontrols are living organisms used to suppress the density of a pest organism's population or its associated impact, rendering it less abundant and less problematic (Eilenberg et al. 2001). However, where the targeted pest organism is parasitic or pathogenic, it is critical to select appropriate biocontrol agents that are not susceptible and which do not pose a risk of enhancing pathogen virulence (cf. Madhusudana Rao \& Lalitha 2015).

Biocontrol use in marine environments remains largely underexplored and is in a current stage of infancy (Atalah et al. 2015). Aquaculture consideration of, and the use of biocontrols against, pathogenic agents has focused largely on the use of microbial control strategies, e.g. probiotics, bacteriophages, and specific predatory bacteria to target economically

\footnotetext{
${ }^{*}$ Corresponding author: david.vaughan@jcu.edu.au
}

important bacterial finfish and shellfish diseases (see examples in Verschuere et al. 2000, Cao et al. 2014, Madhusudana Rao \& Lalitha 2015). To date, the only biocontrol application against fish ectoparasites in commercial aquaculture has been the use of cleaner fishes such as wrasses, Centrolabrus exoletus Linnaeus, 1758, Ctenolabrus rupestris (Linnaeus, 1758), Labrus bergylta Ascanius, 1767, Symphodus melops (Linnaeus, 1758), and lumpfish, Cyclopterus lumpus (Linnaeus, 1758) to control sea lice, Lepeophtheirus salmonis (Krøyer, 1837) and Caligus elongatus von Nordmann, 1832, parasitic on Atlantic salmon Salmo salar Linnaeus, 1758, and other salmonids farmed in marine waters in Europe (Deady et al. 1995, Treasurer 2002, Skiftesvik et al. 2013, Leclercq et al. 2014, Blanco Gonzalez \& de Boer 2017).

The control of sea lice by cleaner fishes follows an augmentative biocontrol approach, which involves

() The authors 2018. Open Access under Creative Commons by Attribution Licence. Use, distribution and reproduction are unrestricted. Authors and original publication must be credited. 
the introduction of indigenous natural predators to control pest organisms (see Atalah et al. 2015). This strategy offers clear benefits in salmon farming by reducing numbers of reproductive adult sea lice. However, the success of this type of biocontrol strategy relies primarily on the feeding preferences of the biocontrol agents (Hajek 2004, Atalah et al. 2015). The utility of the cleaner fishes' model, notably wrasses in Europe, had traditionally been supported by the combination of a specific feeding preference of the selected cleaner species for a few problematic sea lice species (see Blanco Gonzalez \& de Boer 2017), and little overlap of their known parasite diversity with that of the cultured salmon (Treasurer 2012). Nonetheless, recent evidence suggests that cleaner fishes, including lumpfish, are susceptible to other more generalist pathogens important to salmon and other fishes, including C. elongatus, and Paramoeba perurans (Young, Crosbie, Adams, Nowak \& Morrison, 2007) sensu Feehan et al. (2013), the aetiological agent of amoebic gill disease (Karlsbakk et al. 2013, 2014, Karlsbakk 2015, Haugland et al. 2017, Powell et al. 2017). This demonstrates a clear risk of using a cleaner fish model against the pathogens of other fishes, but also the limited scope for using cleaner fishes against other host-parasite models and in other geographical regions.

The Asia-Pacific region produces the majority of the world's aquaculture products, yet no biocontrol use is employed against the ectoparasites of farmed fishes in this region. Recently, Shinn et al. (2015) estimated aquaculture stock losses in parts of Asia to be between 30 and $50 \%$ as a result of parasitic agents, excluding viruses and bacterial pathogens. The diversity of economically important ectoparasites of cultured marine finfish listed by Shinn et al. (2015) for this region is high, represented by many protozoans and metazoans with a direct life cycle, many of which have a wide distribution range and low host specificity (see Shinn et al. 2015). It is therefore unlikely that any cleaner fishes would offer a viable option for ectoparasite biocontrol in tropical finfish aquaculture. A potentially viable alternative may be the use of cleaner shrimp in a similar augmentative biocontrol approach (Vaughan et al. 2018).

There are an estimated 51 cleaner shrimp species known globally (Vaughan et al. 2016) that interact naturally with various client species, of which the majority are marine teleosts. Many cleaner shrimp species directly remove and consume the ectoparasites in a density-dependent manner (e.g. Becker \& Grutter 2005) from their clients through repetitive symbiotic cleaning interactions, and some species are also known to prey on the environmental (benthic) stages of the ectoparasites (e.g. Militz \& Hutson 2015, Vaughan et al. 2018). In so doing, these shrimp can reduce the reinfection pressure on host fishes (Militz \& Hutson 2015). No cleaner shrimp species is known to be susceptible to the ectoparasites of marine fishes, which reflects the co-evolved host specificity of these fish ectoparasites (Poulin 1995), and a subsequent advantage that cleaner shrimp may offer over cleaner fishes in finfish aquaculture. Cleaner shrimp have never been used as a biocontrol agent against fish ectoparasites in commercial aquaculture. However, the gregarious rock shrimp Rhynchocinetes typus H. Milne Edwards, 1837, a non-cleaner species, was used successfully to reduce biofouling of suspended scallop cultures by Dumont et al. (2009). This is the only example of a shrimp being used as a biocontrol in aquaculture, and benefits included reduced mortality and increased growth of the farmed scallops (Dumont et al. 2009).

A large contributor to the ectoparasite problems in aquaculture is the resilience and sheer volume of the benthic stages of the different parasite species. These eggs, cocoons, and cysts remain attached to culture cages and other farm infrastructure and ultimately hatch or release their re-infective stages to infect farm stock in high numbers. A prime example is Neobenedenia girellae (Hargis, 1955), a cosmopolitan monogenean fluke ectoparasite of serious economic concern throughout the Indo-Pacific region (Brazenor et al. 2018a), which is responsible for morbidity and mortality in a diversity of cultured marine fishes including members of Carangidae Rafinesque, 1815, Cichlidae Bonaparte, 1835 (marine acclimated tilapias), Lateolabracidae V. G. Springer \& Raasch, 1965, Latidae Jordan, 1888, Paralichthyidae Regan, 1910, Rachycentridae Gill, 1896, Serranidae Swainson, 1839, and Tetraodontidae Bonaparte, 1831 (Ogawa et al. 1995, Brazenor \& Hutson 2015, Shinn et al. 2015, Shirakashi \& Hirano 2015, Brazenor et al. 2018b). Acute infections of farmed fish with $N$. girellae result in severe mortality events, with fish subjected to stressful conditions or naïve stock without prioracquired immunity most at risk (Deveney et al. 2001, Shirakashi \& Hirano 2015). The traditional control measure for $N$. girellae eggs on fish cages remains the frequent cyclic replacement of contaminated nets with disinfected nets, which is largely ineffective, and which contributes to labour time and cost (Shirakashi \& Hirano 2015).

We recently selected the cleaner shrimp Lysmata vittata (Stimpson, 1860) for testing as the first cleaner shrimp biocontrol candidate under aquaculture con- 
ditions, based on its superior performance at benthic parasite stage reduction in a series of previous laboratory trials (Vaughan et al. 2018). In the present study, we aimed to test the efficacy of $L$. vittata against the benthic egg stage of $N$. girellae on a farmed grouper, Epinephelus lanceolatus (Bloch, 1790) kept in oyster mesh net cages under simulated recirculating aquaculture conditions.

\section{MATERIALS AND METHODS}

\section{Animal ethics and welfare}

Ethical approval was granted prior to commencement of this study under the James Cook University Ethics Committee Permit number A2260, conforming strictly to the national regulations set out by the National Health and Medical Research Council (2013). Fish were subjected to temporary infection by the ectoparasite Neobenedenia girellae. As part of the experiment, freshwater bathing for 5 min using dechlorinated tap water was employed to kill and dislodge $100 \%$ of these ectoparasites (Kaneko et al. 1988) for recovery and counting, and is a routine method used in aquaculture to control ectoparasites (Hutson et al. 2018).

\section{Animals and experimental design}

A total of 480 juvenile Epinephelus lanceolatus from a single cohort ( $150 \mathrm{~mm}$ in total length) were donated for our research by a commercial grouper hatchery in Cairns, Queensland, Australia. All fish were initially given a $5 \mathrm{~min}$ freshwater bath with dechlorinated tap water on arrival before being quarantined together in the commercial trials laboratory of the Marine Parasitology Laboratory (MPL), James Cook University (JCU) for $30 \mathrm{~d}$ on a dedicated marine recirculating life-support system. A total of $120 \mathrm{com}-$ mercially produced peppermint cleaner shrimp Lysmata vittata, also of a single cohort, were purchased from a commercial producer in Tasmania, Australia, and shipped to us once they had reached adulthood ( $30 \mathrm{~mm}$ in total length). On arrival, all cleaner shrimp were quarantined for $30 \mathrm{~d}$ in a separate, isolated recirculating system. During the quarantine period and the experiment, all fish were fed to satiation daily with Ridley Aquafeed marine float commercial marine fish pellets, and the cleaner shrimp were fed daily with defrosted, commercially available Mysis sp. shrimp.
The commercially important monogenean N. girellae is continuously cultured in the separate MPL culture facility at JCU (see Hutson et al. 2018). Prior to experimentation, freshly laid $N$. girellae eggs were isolated from the culture and incubated at $24^{\circ} \mathrm{C}$ in a large glass Petri dish containing fresh, filtered seawater (salinity $=35 \mathrm{ppt}$ ). Eggs were monitored daily under a Leica M60 dissection microscope for embryonic development and hatching (see Hutson et al. 2018). Free-swimming larvae (oncomiracidia) hatched on Day 4 (see Brazenor \& Hutson 2015) and were collected via pipette and counted before immediately being transferred to a glass beaker of fresh, filtered seawater for the experiment.

All fish were transferred to a circular $500 \mathrm{l}$ tank containing fresh, pre-filtered seawater supplied with continuous aeration through an air diffuser. The glass beaker containing 10000 fresh viable oncomiracidia was carefully introduced to the tank of fish, with care to distribute the contents as evenly throughout the tank as possible while maintaining continuous aeration. Fish were cohabited with the oncomiracidia for $1 \mathrm{~h}$. After $1 \mathrm{~h}$, individual fish were netted out using a soft aquarium hand-held net and randomly assigned to 8 identical separate 5001 circular tanks containing an inner plastic oyster mesh cage $11 \mathrm{~m}$ diameter), representing 4 treatment and 4 control replicates (i.e. 60 fish cage ${ }^{-1}$ ). These 4 treatment and 4 control tanks received constant recirculating aerated and biologically filtered seawater. In addition, seawater was recirculated through an algae scrubber containing live, growing Caulerpa taxifolia (M. Vahl) C. Agardh, 1817, for nitrate export. No UV disinfection or foam fractionation was employed, and no seawater exchanges were performed during the experiment. Seawater conditions (Fig. 1) were monitored daily with a Hach hand-held temperature and dissolved oxygen meter, a standard refractometer, a Eutech Scan2 pH meter, and ornamental aquarium nitrogenous waste test kits. Artificial light (cool white fluorescent overhead lighting) was maintained on a $12 \mathrm{~h}$ light:12 $\mathrm{h}$ dark regime.

To establish parasite egg biofouling on the experimental cages, $N$. girellae were allowed to develop on the fish to sexual maturity ( $7 \mathrm{~d}$ post-infection; Brazenor \& Hutson 2015) and an additional $2 \mathrm{~d}$ to allow at least 3 consecutive days' egg production according to the biological data of Brazenor \& Hutson (2015) at $26^{\circ} \mathrm{C}$ and 35 ppt salinity. On Day 9 post-infection, all fish were removed from their oyster mesh cages and given a $5 \mathrm{~min}$ freshwater bath in dechlorinated tap water to kill and remove adult $N$. girellae (see Kaneko et al. 1988), and therefore cease further egg produc- 


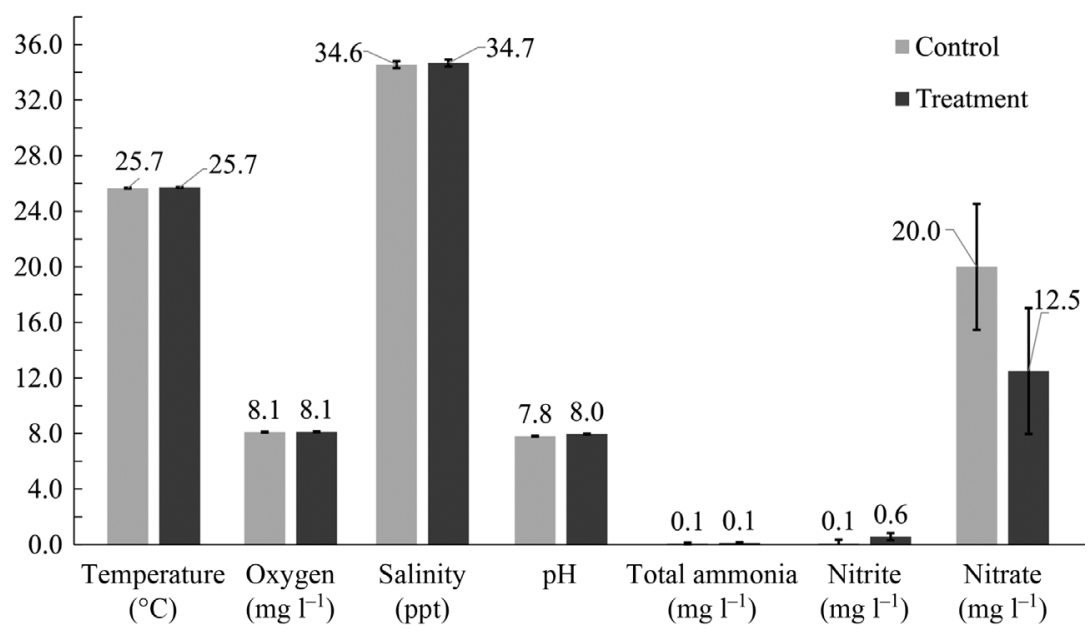

Fig. 1. Mean $( \pm \mathrm{SE})$ water quality parameters recorded for the duration of the experiment

tion, before being returned to their original cages. A mean ( \pm SE) intensity of $18.7 \pm 2$ (range: 11 to 32 ) adult $N$. girellae fish ${ }^{-1}$, representing $\sim 90 \%$ initial infection success, was calculated from a sample of 10 fish and was considered benign for similar-sized hosts by Deveney et al. (2001). Immediately after the fish were returned to their cages, 30 individual adult L. vittata were introduced to each of the 4 treatment tanks to patrol the outside of the oyster mesh cages with entangled monogenean eggs (Fig. 2).

A total of 20 fish were sampled haphazardly from each cage on Days 11, 12, and 13 post-infection, corresponding with hatching of the eggs at $26^{\circ} \mathrm{C}$ and 35 ppt salinity and subsequent recruitment (Brazenor \& Hutson 2015), and were individually given a $5 \mathrm{~min}$

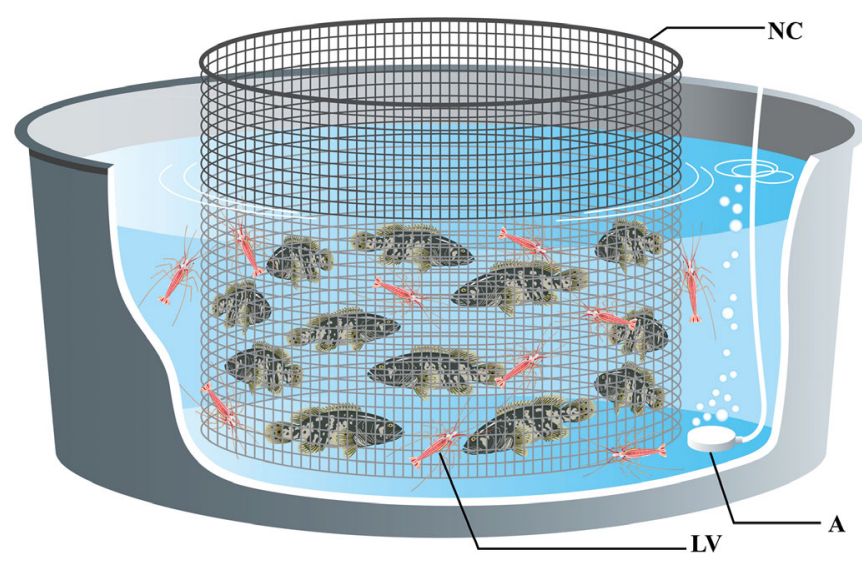

Fig. 2. Graphic representation of a replicate treatment tank containing juvenile Epinephelus lanceolatus inside oyster mesh net cages (NC), and Lysmata vittata (LV) on the out side of the cages. A: constant aeration freshwater bath using separate plastic buckets of dechlorinated tap water. The contents of each bath was filtered through a $23 \mu \mathrm{m}$ sieve, decanted into separate labelled sample jars and preserved in $70 \%$ ethanol for subsequent counting. After their freshwater bath, all fish were introduced to a separate recirculating marine life-support system to recover. There were no fish or shrimp mortalities during the experiment.

Each sample jar was emptied into a large glass Petri dish and its contents inspected under the Leica dissection microscope. All individual N. girellae parasites were collected via pipette, manually counted, and preserved in separate, labelled vials of $70 \%$ ethanol.

\section{Statistical approach}

We used mixed effects random-intercept models to analyse the parasite count data over the 3 sampling days, providing the resolution to optimise data modelling to density-dependent predation of the cleaner shrimp, while accounting for repeated sampling from experimental tanks. Generalised linear regression was not required because parasite count data, which consisted of predominantly high counts and no zeros, when log transformed produced normally distributed residuals (see the Supplement at www.int-res.com/ articles/suppl/q010p429_supp.pdf). In addition, the mixed effects random-intercept models were more applicable to account for different levels of residual variation in the response variable (log of parasite counts) after log transformation (e.g. between days and between treatment; see the Supplement). Water quality data were separately analysed over the entire experiment using a standard linear regression. All analyses were performed in R v.3.4.0 (R Development Core Team 2017). Mixed effects random-intercept models were produced using the package 'nlme' (Pinheiro et al. 2018). All models passed diagnostic scrutiny. We constructed 3 mixed effects randomintercept models; 2 with correlation of variance structures for variance differences in treatment, or treatment-day combination groups, and 1 without a correlation of variance structure (see the Supplement). These models were then compared using the anova() function, and the model accounting for correlation of variance structures for the treatment-day 
combination was considered the most improved model for our data (see the Supplement). The improved model tested the log of parasite counts (the response variable) as a function of treatment (with or without shrimp) and day (the fixed effects), using the interaction terms treatment $\times$ day, and tank as the random effect (see the Supplement).

\section{RESULTS}

Lysmata vittata consumed Neobenedenia girellae eggs entangled on the oyster mesh fish cages (Fig. 3) and subsequently reduced $N$. girellae recruitment by $\sim 87 \%$ (ANOVA: $F_{1,6}=173.36, \mathrm{p}<0.0001$; Fig. 4). A mean $( \pm \mathrm{SE})$ of $964.2 \pm 77.4$ (range: 101 to 9851 ), and $123.4 \pm 3.5$ (12 to 350 ) N. girellae post-larvae were recovered from fish in the control and treatment groups, respectively. Numbers of $N$. girellae on fish across the experiment decreased with time by $\sim 37 \%$ by Day 13 (ANOVA: $F_{2,468}=31.20, \mathrm{p}<0.0001$; Fig. 4 ). The regression results for the fixed effects are presented in Table 1. Water quality parameters were not statistically different between treatment groups (ANOVA: $F_{1,24}=1.27, \mathrm{p}=0.27$ ) and remained stable for the duration of the experiment (see Fig. 1). Temperature and salinity remained at $\sim 26^{\circ} \mathrm{C}$ and $\sim 35$ ppt.

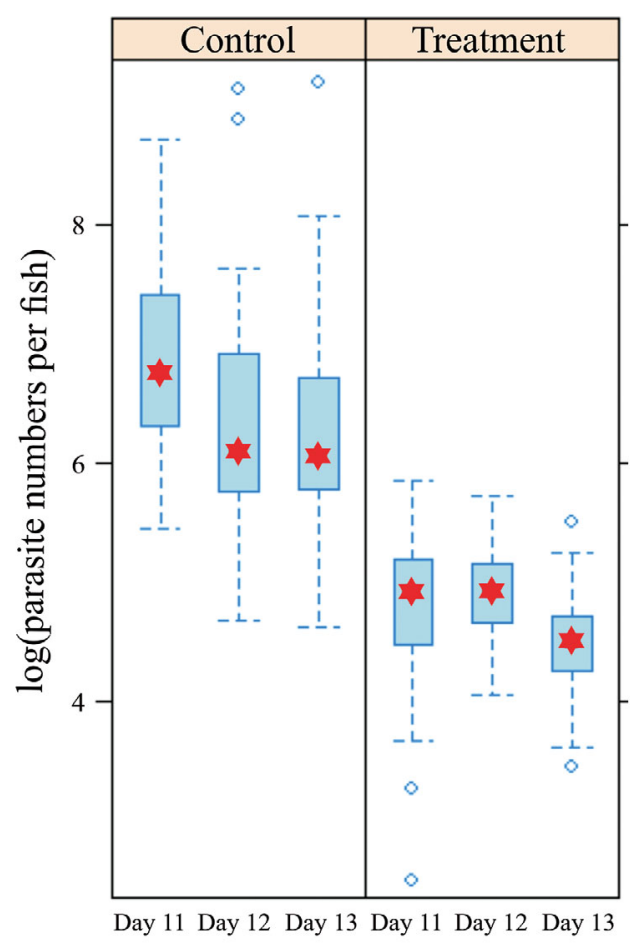

Fig. 4. Effect of Lysmata vittata on the number of Neobenedenia girellae infecting juvenile Epinephelus lanceolatus. Red star: median; boxes are standard $50 \%$ interquartile range; clear circles: outliers generated by the analysis; day: day post-infection
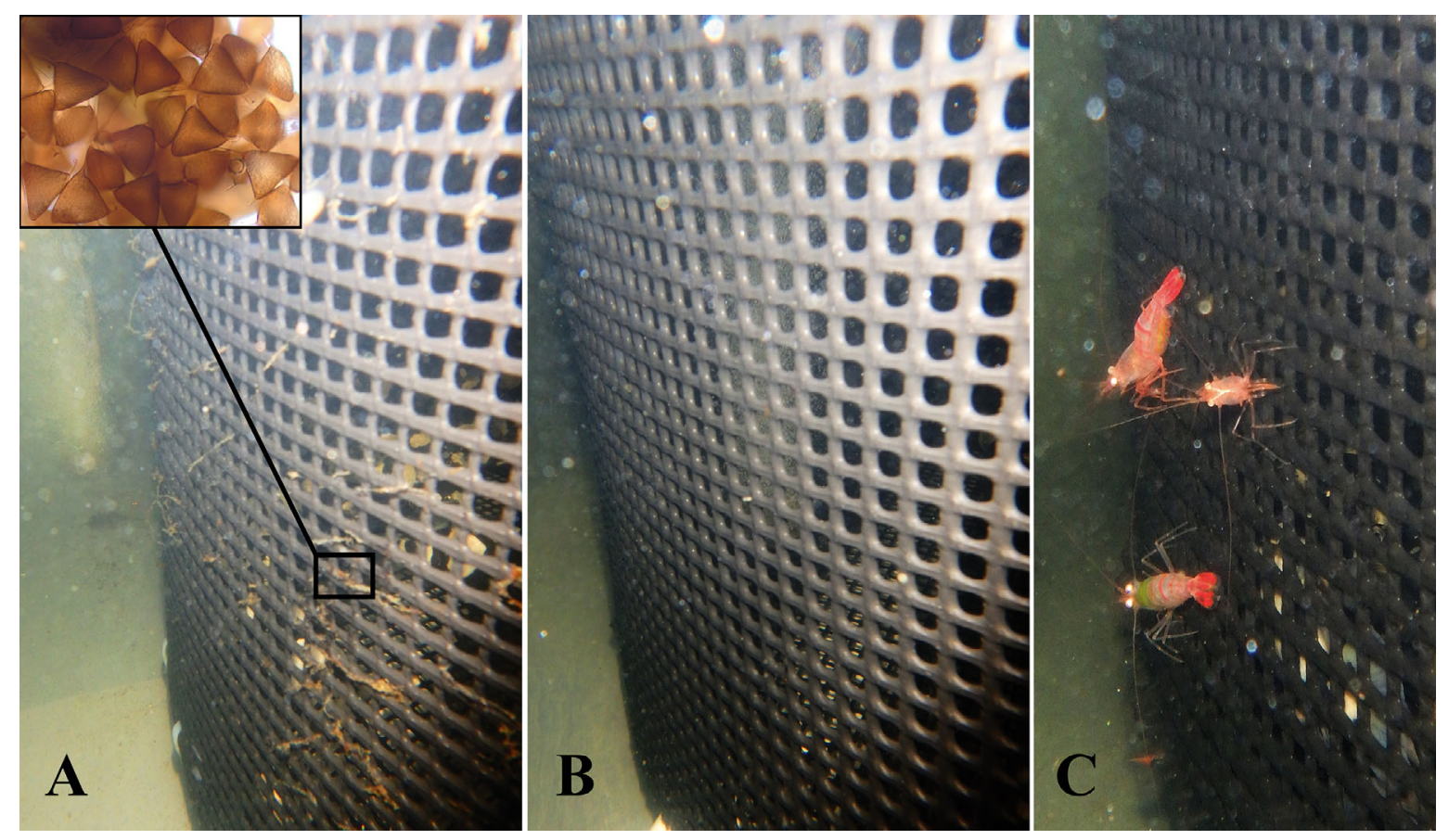

Fig. 3. Underwater photographs of net cages during experimentation; (A) control cage (absence of Lysmata vittata) with accumulation of Neobenedenia girellae egg masses; (B) treatment cage (presence of L. vittata); (C) L. vittata feeding on the external surface of a net cage 
Table 1. Fixed effects regression results

\begin{tabular}{|lrc|}
\hline Fixed effects & $\beta$ & $95 \%$ CI \\
\hline Intercept & 6.88 & {$[6.65,7.10]$} \\
Treatment (shrimp) & -2.11 & {$[-2.50,-1.73]$} \\
Day (Day 12) & -0.62 & {$[-0.86,-0.37]$} \\
Day (Day 13) & -0.60 & {$[-0.83,-0.38]$} \\
Treatment (shrimp): Day (Day 12) & 0.75 & {$[0.47,1.03]$} \\
Treatment (shrimp): Day (Day 13) & 0.32 & {$[0.06,0.60]$} \\
\hline
\end{tabular}

\section{DISCUSSION}

Our results demonstrate for the first time the potential of the cleaner shrimp Lysmata vittata as an effective biocontrol agent under simulated recirculating marine aquaculture conditions, and its potential for use on fish farms. The ability of $L$. vittata to consume Neobenedenia girellae eggs on cage netting is significant because the eggs constitute the main source of reinfection to fishes in aquaculture (Shirakashi \& Hirano 2015) and are resistant to chemical treatments used to control adult parasites on the host fishes (Whittington \& Kearn 2011). The traditional method to control $N$. melleni egg accumulation on farms is the manual replacement of nets; however, the most efficient timing of net changes is unknown, and the daily accumulation of $N$. girellae eggs exacerbates an already labour-intensive and time-consuming farm practice (Shirakashi \& Hirano 2015). Recently, Shirakashi \& Hirano (2015) evaluated some of the distribution dynamics of $N$. girellae eggs in a culture cage in support of the development of novel future egg removal methods. We believe that L. vittata (and possibly other shrimp species) may offer this novel solution, particularly for landbased operations, broodstock facilities, hatcheries, and nurseries, because shrimp are capable of locating and consuming these eggs, which offer a rich source of protein and lipids, including saturated, monounsaturated, and polyunsaturated fatty acids (Brazenor et al. 2017).

To the best of our knowledge, our data also demonstrate for the first time the sudden increase in intensity, and the intensity range, of N. girellae post-larvae for an entire susceptible captive host population within days of an initial benign infection. A sudden outbreak of $N$. girellae (sec. Brazenor et al. 2018b) was considered the reason for the acute mortality of 200000 farmed barramundi Lates calcarifer (Bloch, 1790) in the Hinchinbrook Channel in Northern Queensland, Australia (Deveney et al. 2001). A contributing factor was thought to be a precluding period of unfavourable environmental conditions for the fish. Following this initial mass mortality event, and the return to optimal environmental conditions, the surviving fish appeared to make a rapid recovery (Deveney et al. 2001).

Cleaner shrimp in both tropical and temperate environments are known to prey on the ectoparasites of fishes (see Vaughan et al. 2016 for species), but it is likely that only the gregarious species, like $L$. vittata, would offer any meaningful benefit to aquaculture, as individuals of these species naturally occur together in groups, unlike the pair-forming species which are intolerant of additional conspecifics (Wong \& Michiels 2011). L. vittata has a natural distribution extending throughout the Indo-Pacific (Palomares \& Pauly 2018), which includes the major marine aquaculture producing nations. It is currently cultured commercially in Australia for the ornamental trade and has the potential for large-scale development. $L$. vittata may also be effective against other fish ectoparasites in aquaculture. In our recent laboratory trials (Vaughan et al. 2018), L. vittata was effective at reducing and consuming the benthic stages of the ciliophoran ectoparasite Cryptocaryon irritans Brown, 1951, and the cocoons of the marine leech Zeylanicobdella arugamensis de Silva, 1963. Its efficiency against these and other ectoparasites remains to be tested under farm conditions. However, cleaner shrimp biocontrol models may offer a solution to sympatric infestations, which are often a reality in aquaculture. Cleaner shrimp and other shrimp species should therefore continue to be explored for a future role in aquaculture biocontrol, as originally proposed by Becker \& Grutter (2004). Hints of the success of using shrimp in biocontrol already exist in the literature; Rhynchocinetes typus has been used to reduce net biofouling of scallop cages in Chile (Dumont et al. 2009), while the experimental field trial use of the native freshwater shrimp Macrobrachium vollenhoveni (Herklots, 1857) in parts of the Senegal River reduced the prevalence of human schistosomiasis by predation on the snail intermediate host (Sokolow et al. 2015).

Historically, the cleaner fishes biocontrol model has contributed significantly to the reduction of sea lice in European salmon farming (Blanco Gonzalez \& de Boer 2017) and reduced reliance on drugs and chemical treatments to control sea lice outbreaks (Treasurer 2002, Powell et al. 2017), thereby reducing the impact of disease and mandatory drug withdrawal periods prior to harvesting. The development and application of cleaner shrimp biocontrols could have a similar result in aquaculture, particularly in sub-tropical and 
tropical regions where stock losses from ectoparasites are high (Shinn et al. 2015), and where cleaner fishes are an unlikely option. The global financial loss from pathogens in aquaculture is estimated to be approximately $20 \%$ of the total production value (SitjáBobadilla \& Oidtmann 2017). Financial losses are linked to livestock mortalities, the impact of nonlethal infections on livestock growth performance, the market rejection of diseased livestock (e.g. Ogawa 1994, Moran et al. 1999), and the associated costs of mitigating diseases (Lafferty et al. 2015). Diseases in general are considered the most significant constraint to future global aquaculture expansion (Stentiford et al. 2017) and will undoubtedly be influenced by the increasing incidence of pathogen resistance to treatments (cf. Conly \& Johnston 2005, Done et al. 2015, Watts et al. 2017). Indeed, the development of the cleaner fishes model was driven largely by the increase in resistance of sea lice to chemical therapies (Costello et al. 2001, Costello 2006, Aaen et al. 2015). It is therefore likely that alternative controls against ectoparasites in finfish aquaculture will continue to attract increasing interest and support globally. Biocontrols offer considerable potential in this regard, particularly if included as part of a holistic integrated pest management strategy (Mordue \& Pike 2002, Brooks 2009, Sitjá-Bobadilla \& Oidtmann 2017) to combine multiple dynamic approaches to disease challenges (Aaen et al. 2015).

Acknowledgements. This study was supported by a James Cook University Development Grant, 'Parasite cultivation techniques: in vitro and in vivo culture methods for ecological and applied aquatic parasitology research' awarded to K.S.H. We are grateful to Ben Lawes, Simon Wever, and Andrew Thompson of the Marine and Aquaculture Research Facilities Unit at James Cook University for their assistance in building the experimental recirculating aquaculture system. We are equally grateful to Dr. Richard Knuckey from The Company One, Cairns, for the donation of the cultured Epinephelus lanceolatus, and to Sea Horse World, Tasmania, for specifically culturing the number of Lysmata vittata required for this project and their punctual delivery. Thank you to Alejandro Trujillo-González for his assistance with sampling, and to Emeritus Professor Rhondda Jones for recommending the specific statistical methodology. We thank Eden Cartwright (Bud Design Studio) for graphic art (Fig. 2). D.B.V. was supported by a James Cook University International Postgraduate Research Scholarship.

\section{LITERATURE CITED}

Aaen SM, Helgesen KO, Bakke MJ, Kaur K, Horsberg TE (2015) Drug resistance in sea lice: a threat to salmonid aquaculture. Trends Parasitol 31:72-81

Atalah J, Hopkins GA, Fletcher LM, Castinel A, Forrest BM
(2015) Concepts for biocontrol in marine environments: Is there a way forward? Manage Biol Invasions 6:1-12

Becker JHA, Grutter AS (2004) Cleaner shrimp do clean. Coral Reefs 23:515-520

Becker JHA, Grutter AS (2005) Client fish ectoparasite loads and cleaner shrimp Urocaridella sp. c hunger levels affect cleaning behaviour. Anim Behav 70:991-996

Blanco Gonzalez E, de Boer F (2017) The development of the Norwegian wrasse fishery and the use of wrasses as cleaner fish in the salmon aquaculture industry. Fish Sci 83:661-670

* Brazenor AK, Hutson KS (2015) Effects of temperature and salinity on the life cycle of Neobenedenia sp. (Monogenea: Capsalidae) infecting farmed barramundi (Lates calcarifer). Parasitol Res 114:1875-1886

Brazenor AK, Francis DS, Hutson KS, Carton AG (2017) Biochemical composition of marine monogenean parasite eggs. Mol Biochem Parasitol 218:1-3

Brazenor AK, Saunders RJ, Miller TL, Hutson KS (2018a) Morphological variation in the cosmopolitan fish parasite Neobenedenia girellae (Capsaliddae: Monogenea). Int J Parasitol 48:125-134

* Brazenor AK, Bertozzi T, Miller T, Whittington ID, Hutson KS (2018b) DNA profiling reveals Neobenedenia girellae as the primary culprit in global fisheries and aquaculture. Mol Phylogenet Evol, doi:10.1016/j.ympev.2018.05.012

*Books KM (2009) Considerations in developing an integrated pest management programme for control of sea lice on farmed salmon in Pacific Canada. J Fish Dis 32: 59-73

Cao H, Hou S, He S, Lu L, Yang X (2014) Identification of a Bacteriovorax sp. isolate as a potential biocontrol bacterium against snakehead fish-pathogenic Aeromonas veronii. J Fish Dis 37:283-289

* Conly JM, Johnston BL (2005) Where are all the new antibiotics? The new antibiotic paradox. Can J Infect Dis Med Microbiol 16:159-160

Costello MJ (2006) Ecology of sea lice parasitic on farmed and wild fish. Trends Parasitol 22:475-483

* Costello MJ, Grant A, Davies IM, Cecchini S, Papoutsoglou S, Quigley D, Saroglia M (2001) The control of chemicals used in aquaculture in Europe. J Appl Ichthyology 17: $173-180$

* Deady S, Varian SJA, Fives JM (1995) The use of cleanerfish to control sea lice on two Irish salmon (Salmo salar) farms with particular reference to wrasse behaviour in salmon cages. Aquaculture 131:73-90

* Deveney MR, Chisholm LA, Whittington ID (2001) First published record of the pathogenic monogenean parasite Neobenedenia melleni (Capsalidae) from Australia. Dis Aquat Org 46:79-82

* Done HY, Venkatesan AK, Halden RU (2015) Does the recent growth of aquaculture create antibiotic resistance threats different from those associated with land animal production in agriculture? AAPS J 17:513-524

* Dumont CP, Urriago JD, Abarca A, Gaymer CF, Thiel M (2009) The native rock shrimp Rhynchocinetes typus as a biological control of fouling in suspended scallop cultures. Aquaculture 292:74-79

* Eilenberg J, Hajek A, Lomer C (2001) Suggestions for unifying the terminology in biological control. BioControl 46: $387-400$

Feehan CJ, Johnson-Mackinnon J, Scheibling RE, LauzonGuay JS, Simpson AGB (2013) Validating the identity of Paramoeba invadens, the causative agent of recurrent 
mass mortality of sea urchins in Nova Scotia, Canada. Dis Aquat Org 103:209-227

Hajek AE (2004) Natural enemies: an introduction to biological control. Cambridge University Press, Cambridge

Haugland GT, Olsen AB, Rønneseth A, Andersen L (2017) Lumpfish (Cyclopterus lumpus L.) develop amoebic gill disease (AGD) after experimental challenge with Paramoeba perurans and can transfer amoebae to Atlantic salmon (Salmo salar L.). Aquaculture 478:48-55

*Hutson KS, Brazenor AK, Vaughan DB, Trujillo-González A (2018) Monogenean parasite cultures: current techniques and recent advances. Adv Parasitol 99:61-91

Kaneko JJ II, Yamada R, Brock JA, Nakamura RM (1988) Infection of tilapia, Oreochromis mossambicus (Trewavas), by a marine monogenean, Neobenedenia melleni (MacCallum, 1927) Yamaguti, 1963 in Kaneohe Bay, Hawaii, USA, and its treatment. J Fish Dis 11:295-300

Karlsbakk E (2015) Amøbisk gjellesykdom (AGD)-litt om den nye plagen. Havforskningsrapporten. www.imr.no/ filarkiv/2015/03/amobisk_gjellesykdom_agd.pdf/nb-no

Karlsbakk E, Olsen AB, Einen ACB, Mo TA and others (2013) Amoebic gill disease due to Paramoeba perurans in ballan wrasse (Labrus bergylta). Aquaculture 412-413:41-44

Karlsbakk E, Alarcon M, Hansen H, Nylund A (2014) Sykdom og parasitter i vill og oppdrettet rognkjeks. Havforskningsrapporten. www.imr.no/filarkiv/2014/03/sykdom_og_parasitter_i_vill_og_oppdrettet_rognkjeks.pdf/

Lafferty KD, Harvell CD, Conrad JM, Friedman CS and others (2015) Infectious diseases affect marine fisheries and aquaculture economics. Annu Rev Mar Sci 7:471-496

Leclercq E, Davie A, Migaud H (2014) Delousing efficiency of farmed ballan wrasse (Labrus bergylta) against Lepeophtheirus salmonis infecting Atlantic salmon (Salmo salar) posts-molts. Pest Manag Sci 70:1274-1282

*Madhusudana Rao B, Lalitha KV (2015) Bacteriophages for aquaculture: are they beneficial or inimical. Aquaculture 437:146-154

Militz TA, Hutson KS (2015) Beyond symbiosis: cleaner shrimp clean up in culture. PLOS ONE 10:e0117723

Moran JDW, Whitaker DJ, Kent ML (1999) A review of the myxosporean genus Kudoa Meglitsch, 1947, and its impact on the international aquaculture industry and commercial fisheries. Aquaculture 172:163-196

Mordue (Luntz) AJ, Pike AW (2002) Salmon farming: towards an integrated pest management strategy for sea lice. Pest Manag Sci 58:513-514

National Health and Medical Research Council (2013) Australian code for the care and use of animals for scientific purposes, $8^{\text {th }}$ edn. National Health and Medical Research Council, Canberra

* Ogawa K (1994) Anoplodiscus tai sp. nov. (Monogenea: Anoplodiscidae) from cultured red sea bream Pagrus major. Fish Pathol 29:5-10

Ogawa K, Bondad-Reantasso MG, Fukudome M, Wakabayashi H (1995) Neobenedenia girellae (Hargis, 1955) Yamaguti, 1963 (Monogenea: Capsalidae) from cultured marine fishes of Japan. J Parasitol 81:223-227

Palomares MLD, Pauly D (2018) SeaLifeBase. https://www. sealifebase.ca/ (accessed 13 May 2018)

* Pinheiro J, Bates D, DebRoy S, Sarkar D, R Core Team

Editorial responsibility: Bengt Finstad,

Trondheim, Norway
(2018) nlme: linear and nonlinear mixed effects models. $\mathrm{R}$ package version 3.1-131.1. https://CRAN.R-project. org/package=nlme

* Poulin R (1995) Phylogeny, ecology and the richness of parasite communities in vertebrates. Ecol Monogr 65:283-302

* Powell A, Treasurer JW, Pooley CL, Keay AJ, Lloyd R, Imsland A, García de Leaniz C (2017) Use of lumpfish for sealice control in salmon farming: challenges and opportunities. Rev Aquacult 10:683-702

R Development Core Team (2017) R: a language and environment for statistical computing. R Foundation for Statistical Computing, Vienna. www.r-project.org

Shinn AP, Pratoomyot J, Bron LE, Paladini G, Brooker EE, Brooker AJ (2015) Economic costs of protistan and metazoan parasites to global mariculture. Parasitology 142: $196-270$

Shirakashi S, Hirano C (2015) Accumulation and distribution of skin fluke Neobenedenia girellae eggs on a culture cage. Aquaculture 443:1-4

Sitjá-Bobadilla A, Oidtmann B (2017) Integrated pathogen management strategies in fish farming. In: Jeney J (ed) Fish diseases: prevention and control strategies. Academic Press, London, p 119-146

Skiftesvik AB, Bjelland RM, Durif CMF, Johansen IS, Browman HI (2013) Delousing of Atlantic salmon (Salmo salar) by cultured vs. wild ballan wrasse (Labrus bergylta). Aquaculture 402-403:113-118

* Sokolow SH, Huttinger E, Jouanard N, Hsieh MH and others (2015) Reduced transmission of human schistosomiasis after restoration of a native river prawn that preys on the snail intermediate host. Proc Natl Acad Sci USA 112: 9650-9655

* Stentiford GD, Sritunyalucksana K, Flegel TW, Williams BAP, Withyachumnarnkul B, Itsathitphaisarn O, Bass D (2017) New paradigms to help solve the global aquaculture disease crisis. PLOS Pathog 13:e1006160

* Treasurer JW (2002) A review of potential pathogens of sea lice and the application of cleaner fish in biological control. Pest Manag Sci 58:546-558

Treasurer JW (2012) Diseases of north European wrasse (Labridae) and possible interactions with cohabited farmed salmon, Salmo salar L. J Fish Dis 35:555-562

*Vaughan DB, Grutter AS, Costello MJ, Hutson KS (2016) Cleaner fishes and shrimp diversity and a re-evaluation of cleaning symbioses. Fish Fish 18:698-716

*Vaughan DB, Grutter AS, Hutson KS (2018) Cleaner shrimp are a sustainable option to treat parasitic disease in farmed fish. Sci Rep, doi:10.1038/s41598-018-32293-6

Verschuere L, Rombaut G, Sorgeloos P, Verstraete W (2000) Probiotic bacteria as biological control agents in aquaculture. Microbiol Mol Biol Rev 64:655-671

Watts JEM, Schreier HJ, Lanska L, Hale MS (2017) The rising tide of antimicrobial resistance in aquaculture: sources, sinks and solutions. Mar Drugs 15:158

* Whittington ID, Kearn GC (2011) Hatching strategies in monogenean (Platyhelminth) parasites that facilitate host infection. Integr Comp Biol 51:91-99

*Wong JW, Michiels NK (2011) Control of social monogamy through aggression in a hermaphroditic shrimp. Front Zool 8:30

Submitted: May 15, 2018; Accepted: August 6, 2018 Proofs received from author(s): September 13, 2018 